\title{
Kinds of minds
}

\section{Do differences in history, culture and education influence whether scientists focus on pieces and particulars, or make broad connections?}

\section{David Knight}

A hundred years ago, the philosopherphysicist Pierre Duhem, looking back over the nineteenth century, saw two kinds of scientific minds: the French, strongly focused, narrow and deep; and the English, ample, broad and shallow. As nationalism, Duhem's scheme failed: his 'French' minds included Newton's and his 'English' ones Napoleon Bonaparte's. What stands is his conviction that two different approaches - a reductionist focus on parts and particulars, and a broader approach that seeks to connect up the pieces - are needed in science.

But was Duhem right to imply that differences in culture, history and education led to the predominance of one or other mode of thinking? A brief glance at science and its practitioners in the past suggests he may have been.

In the mid-1600s, mechanical clocks were triumphs of modern ingenuity. In the aftermath of England's civil war and religious strife, a state that ran like clockwork must have seemed a wonderful idea. The appeal of order almost certainly influenced Robert Boyle and his contemporaries, who saw the world as an enormous clock. The natural philosopher's job was to discover this clock's minute components and indicate how, fitted together, they accounted for what we saw around us. In appearance, there were colours, tastes and smells; in reality, atoms and the void. The familiar world should be reduced to the shape and composition of particles, and the strength of the forces that held them together.

Around 1800, this emphasis on extracting and analysing the bits and pieces that make up the whole became particularly prominent. Scientific education, research laboratories, museums and professional careers in science opened up in what was then the scientific centre of the world Paris. Patronage shifted from grandees to newly professional scientists, and the 'big pictures' beloved of Enlightenment figures such as James Hutton and Jean-Baptiste Lamarck were rejected in favour of definite and quantified results, careful observations and taxonomic descriptions, laws testable by experiment, and mathematical analysis.

From about 1780, times in France had been interesting and dangerous: the economic crisis led in 1789 to revolution, and in 1794 to terror and the chemist Antoine Lavoisier's execution. World war raged from 1793 to 1815 , when with Napoleon's exile the monarchy was restored. Distinct, exact and reductive science was the fashion, and the safest bet. The German chemist Justus Liebig was among those inspired by his time spent in Paris. When he returned to the little university of Giessen, he began training cohorts of research students in techniques of analysis, and, faced with the problems of the hungry forties, he pursued clear and reductive work on physiology and agriculture.

To Liebig's horror (he saw it as a 'black death'), elsewhere in Germany, and in England, the Romantic movement was taking hold: a reaction against this world of little things. Romanticism insisted that true seers look upwards (Newton in William Blake's famous image is looking at the ground). Imagination, feeling, life and organic unity became watchwords, and a truly dynamic science the goal. In England, Humphry Davy delighted his friends Samuel Taylor Coleridge and Walter Scott with his ampleminded perception that chemical affinity and electricity were manifestations of one power, leading him to isolate potassium and other metals in 1807.

But the broadest mind of that time was Berlin-born Alexander von Humboldt's. Travelling along rivers in Latin America, Humboldt noted curious linkages between them; he established latitudes and longitudes; made ethnographic observations; collected from the animal, vegetable and mineral kingdoms; and studied volcanoes. He climbed higher than anybody had been previously, collecting samples of air from his highest point, on Chimborazo.

In the Andes he had gone up from a tropical world through a temperate zone to a region of ice and snow reminiscent of Spitzbergen. He reflected on plant distribution, and devised maps drawn with theoretical lines such as isotherms (indicating matched mean temperatures). His great work in middle life was to promote international cooperation in observing terrestrial magnetism and other global phenomena. His writings were vivid, personal and yet objective attempts to connect everything, and communicate his vision.

Humboldt's ample mind, inspired in part by the Romantic movement, delighted Charles Darwin, who in 1859 brought together in a great synthesis a vast mass of botanical, zoological, geological and geographical material. In that same decade, Hermann Helmholtz, embracing physics after working in medicine, announced his clear perception of conservation of energy. His wide-ranging mind meant that he could state clearly what many people had been perceiving indistinctly, or only as special cases: in effect, he founded classical physics as the science of energy and its transformations, seizing from chemistry its previously fundamental position. The Romantic movement spawned a time of big-picture thinking. Later, the rise of specialized scientific institutions - and a narrower education and training - produced experts, focused on trees rather than woods, and put scientific imagination under stricter control. Confidence in finding truth goes perhaps with the ample mind, caution in avoiding error with narrower focus. Kinds of minds may be innate, but we are creatures of context, of time, place and zeitgeist. Emerging like the Romantics in a new century after a time of triumphant reductionism focused on molecules and particles, we are ready for confident new syntheses.

David Knight is in the Philosophy Department at Durham University, 50 Old Elvet, Durham DH1 3AY, UK.

FURTHER READING

Brock, W. H. Justus von Liebig: the Chemical Gatekeeper (Cambridge Univ. Press, Cambridge, 1997).

Crosland, M. P. Science Under Control: The French

Academy of Sciences, 1795-1914 11-49 (Cambridge Univ. Press, Cambridge, 1992).

Knight, D. M. Public Understanding of Science: a History of Communicating Scientific Ideas 1-12 (Routledge, London, 2006).

Richards, R. J. The Romantic Conception of Life: Science and Philosophy in the Age of Goethe (Chicago Univ. Press, Chicago, 2002).

For other essays in this series, see http:// nature.com/nature/focus/arts/connections/ index.html 